\title{
Online Value Co-Creation in the Healthcare Service Ecosystem: A Review
}

\section{Atae Rezaei Aghdam}

School of Information Systems

Queensland University of Technology (QUT)

Brisbane, Australia

Email: atae.rezaeiaghdam@hdr.qut.edu.au

\section{Jason Watson}

School of Information Systems

Queensland University of Technology (QUT)

Brisbane, Australia

Email: ja.watson@qut.edu.au

\section{Hasti Ziaimatin}

School of Information Systems

Queensland University of Technology (QUT)

Brisbane, Australia

Email: hastim.matin@gmail.com

\section{Abstract}

Nowadays, the role of patients in the healthcare domain is extending beyond being passive healthcare recipients to becoming "makers and shapers" of healthcare services. In the healthcare service ecosystem, Online Health Communities (OHCs) foster co-creation among the different actors. Over the last five years, a number of articles that focus on value co-creation in the healthcare services have surfaced that highlight the significance of the interactions and engagements between the healthcare ecosystem levels. Accordingly, this paper aims to conduct a systematic review of the literature focusing on the role of OHCs as facilitators of value co-creation in the healthcare service ecosystem. A systematic review of the literature was conducted with articles published between 2013 and 2018. Thematic analysis revealed three key themes including "value is ubiquitous", "online resources connectivism", and "informational and emotional support". This paper provides a structured overview of the current literature and identifies opportunities for future research.

Keywords Value co-creation, online health communities, healthcare ecosystem, service ecosystem 


\section{Introduction}

Value co-creation is described in the literature as consumers coming together with suppliers, service providers or other consumers to create benefits realised by the user in the consumption process (Lusch et al. 2007; Nambisan and Nambisan 2009; Vargo and Lusch 2004). The customer can play a role as product conceptualiser, product designers, product testers, and product marketers in the co-creation process (Nambisan 2002; Nambisan and Nambisan 2008). In the healthcare context, value co-creation refers to "activities centred around the individual patient or in collaboration with numbers of the service delivery network including the patient, family, friends, other patients, health professionals and the outside community" (McColl-Kennedy et al. 2012, p. 6). One of the platforms that can facilitate cocreation in the healthcare ecosystem is online communities (Nambisan and Nambisan 2009). The process of value co-creation occurs in online communities between customers or peers in a process commonly known as peer production (Tapscott and Williams 2008), co-production (Peters et al. 2012), or social production (Arvidsson 2008) among other terms. In recent years, the concept of value cocreation has been discussed in terms of an adapting ecosystem, which continuously improves the system's capabilities for responding to new opportunities (Romero and Molina 2011; Vargo and Lusch 2011). Understanding the holistic aspects of what is a complex system requires a shift from a firmcentred perspective to focusing on the entire context of a complex world (Gummesson 2008). This viewpoint makes a complex context such as healthcare more understandable by adopting system-level thinking. Therefore, in this context, it is important to investigate value co-creation at various levels of aggregation (Lusch and Spohrer 2012). Value co-creation plays an indispensable role in shaping the service ecosystem (Frow et al. 2016), and actors participation in co-creating value in healthcare has received much credence in healthcare research (Osei-Frimpong et al. 2018). In essence, a service ecosystem perspective provides new visions toward value co-creation by emphasising the role of multiple actors and their value co-creation interactions (Lusch and Vargo 2014), the significance of interdependencies, adaptation, and evolution (Frow et al. 2014). In a previous research study, (Beirão et al. 2017), suggested that the healthcare ecosystem needs to facilitate value co-creation. It assists ecosystem managers to make sure that resource integration is facilitated to foster benefits for all actors for engaging in value co-creation activities (Beirão et al. 2017). Co-creation practice created by various actors, belonging to different service ecosystems levels (micro, meso, and macro), show a mutual adjustment and contribute to ongoing shared changes (Ciasullo et al. 2017). In a service ecosystem, the process of value co-creation is impacted by actors' abilities to access, adapt, and integrate resources that are severely shaped by the social context such as relationship and resources (Akaka et al. 2013; Pinho et al. 2014). Actors in such an ecosystem are engaged to share their resources, responding to value propositions which offer the possibility for positive outcomes (Frow et al. 2016). In line with this, the outcome of health co-creation takes place not only in light of patients' demands, requirements, expectations, and experiences but also "with" the patient, who plays the main partner of healthcare professionals and a fundamental value co-creator (Ciasullo et al. 2017). Likewise, with the rapid growth of social media technology, online communities have been provided as ideal platforms for fostering cocreation between the different actors in healthcare service ecosystem (Amann 2017; Nambisan and Nambisan 2009). Hence, it is essential to investigate an integrated ecosystem perspective to understand the impact of OHCs as facilitators for value co-creation process in healthcare service ecosystem. As such, the main aim of this study is to address the following research question:

1) What is the role of online health communities as facilitators of value co-creation in the healthcare service ecosystem?

The remainder of this paper is organised in the following manner; Section 2; explains the research methodology employed in this paper, Section 3; presents the results of the thematic analysis, and finally, in section 4 and 5 , the paper concludes and discusses the opportunities for future research.

\section{Research Methodology}

A systematic literature review of the most relevant articles to the research question was performed with articles published between 2013 and 2018. Most of the pertinent studies were collected from information-system related publications such as Information Systems Electronic Library (AISeL) and PubMed database. Among the 329 identified articles, a total number of 22 articles complied with the following inclusion criteria: 1) articles were written in English 2) published between 2013 and 2018 3) focus on value co-creation in online health communities through different stakeholders in the healthcare service ecosystem. Details of the database searches are presented in table 1. 


\begin{tabular}{lll}
\hline Database & $\begin{array}{l}\text { Keywords } \\
\text { search }\end{array}$ & $\begin{array}{l}\text { Final } \\
\text { selections }\end{array}$ \\
\hline EBSCO & 11 & 4 \\
Scopus & 14 & 3 \\
Medline & 19 & 2 \\
PubMed & 157 & 8 \\
AISeL & 102 & 3 \\
Google & 26 & 2 \\
scholar & & \\
Total & 329 & 22 \\
\hline
\end{tabular}

Table 1. Database search details

The search results were acquired by searching the main keywords including "value co-creation", "healthcare service ecosystem", and "online health communities". According to our research aim, a research string was defined using Boolean "AND" and "OR" operators: ("value co-creation") OR ("online value co-creation") AND ("online health communities" OR "Virtual health communities") AND ("Healthcare service ecosystem"). However, we did not merely focus on these specific terminologies because some papers discussed value co-creation activities by different stakeholders without using the specific terms such as "online value co-creation" or "healthcare service ecosystem". Hence, for ensuring that relevant papers are not neglected in this study, we included other relevant terms in the searching process. For instance, for the EBSCO database, a variant of the above string was applied to ensure that important relevant studies are not omitted. The initial database search strategy resulted in 329 papers, out of which 95 papers were assessed for inclusion criteria and finally 22 papers were selected as the most relevant papers for this review. During the study selection process, 234 out of 329 titles and abstracts of articles were screened by authors and discarded from the article selection process. The rest of 95 articles were fully reviewed and finally, 22 most relevant articles were selected in the final stage. Figure 1 illustrates the stages of article selections;

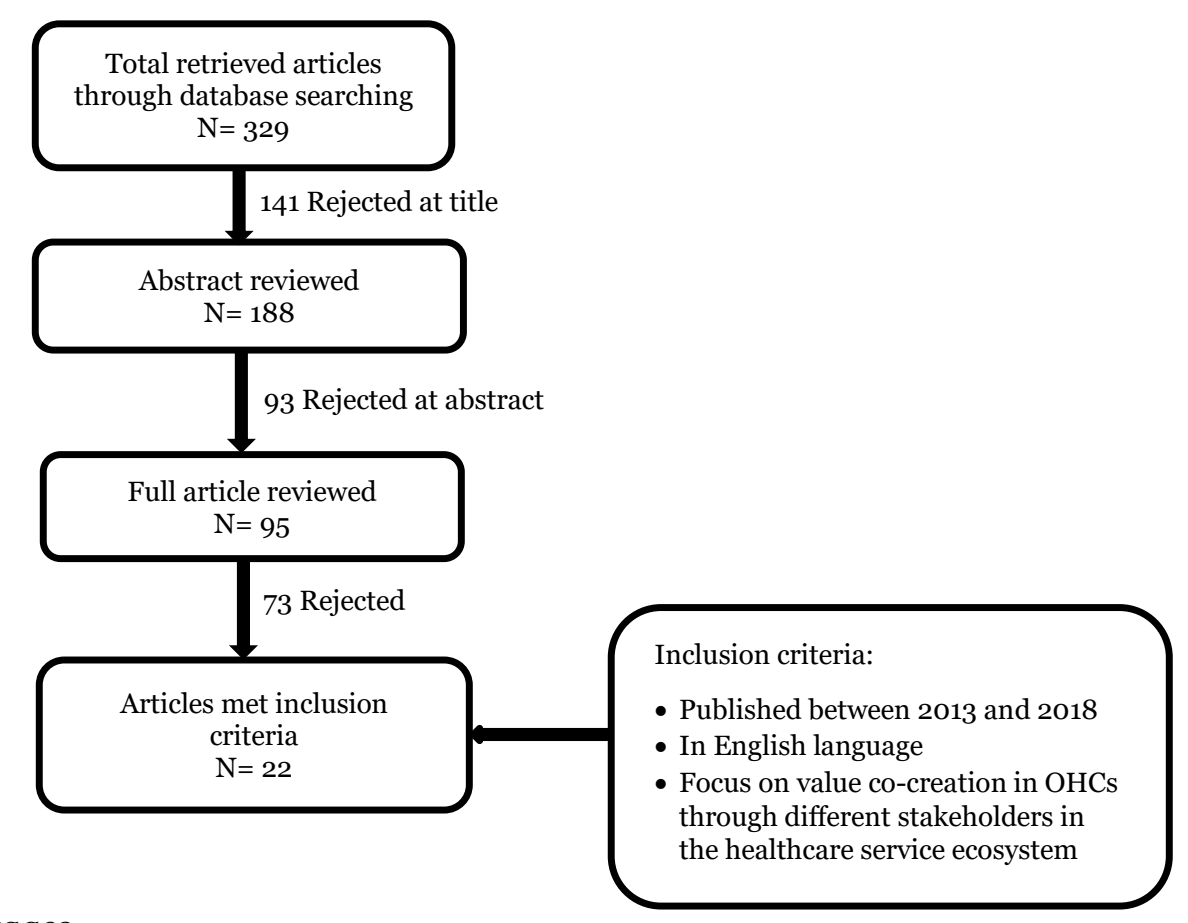

Figure 2: publication selection stages

In order to identify the main themes of chosen articles, "Thematic Analysis" has been carried out in this study. Thematic analysis is a technique to identify, analyse, and report the patterns (themes) within data 
(Braun and Clarke 2006). In doing so, we followed Braun and Clarke (2006) six steps of thematic analysis, which is contextualised in table 2.

\begin{tabular}{|l|l|}
\hline \multicolumn{1}{|c|}{ Phase } & \multicolumn{1}{|c|}{ Contextualisation of the process } \\
\hline $\begin{array}{l}\text { 1. Familiarisation } \\
\text { with data }\end{array}$ & $\begin{array}{l}\text { Our data is the most relevant articles published in the last five years regarding } \\
\text { the role of online health communities as facilitators of value co-creation in } \\
\text { the healthcare service ecosystem. }\end{array}$ \\
\hline $\begin{array}{l}\text { 2. Generating } \\
\text { initial codes }\end{array}$ & Dearching for \\
themes & $\begin{array}{l}\text { Re-focus the analysis from the extensive level of themes and sorting the } \\
\text { diverse codes into potential themes and sub-themes. After re-focusing the } \\
\text { initial codes, we combined some similar themes with each other and conclude } \\
\text { with } 14 \text { general themes. }\end{array}$ \\
\hline $\begin{array}{l}\text { 4. Reviewing } \\
\text { themes }\end{array}$ & $\begin{array}{l}\text { Some candidate themes were eliminated from the process due to the less } \\
\text { relevance to the research question, however, some themes broke down into } \\
\text { separate themes. In addition, in this level, any additional data that had been } \\
\text { missed earlier coding stage have been coded. }\end{array}$ \\
\hline $\begin{array}{l}\text { 5. Defining and } \\
\text { naming themes }\end{array}$ & $\begin{array}{l}\text { Refine the themes and choose the final themes by combining similar themes, } \\
\text { identifying the essence of each theme and determining what aspect of each } \\
\text { theme captured. The naming of themes conducted in this phase in order to } \\
\text { give the reader a sense of what the theme is about. }\end{array}$ \\
\hline $\begin{array}{l}\text { 6. Producing the } \\
\text { report }\end{array}$ & $\begin{array}{l}\text { Producing a concise, coherent and logical story the data tell within and across } \\
\text { themes. After performing this phase, the fourteen general themes grouped } \\
\text { into three main constructs including; "value is ubiquitous", "online resources } \\
\text { connectivism", and "informational and emotional online support". All themes } \\
\text { and sub-themes were vetted during a team meeting. }\end{array}$ \\
\hline and
\end{tabular}

Table 2. Thematic analysis phases

In terms of testing the trustworthiness of the findings of this paper, we employed per cent agreement as our method of inter-coder reliability checking (Nili et al. 2017). Per cent agreement is a simple and useful method of checking the reliability of the qualitative findings of less sensitive (e.g. literature review) IS projects (Nili et al. 2018), where the original analyst and a second person compare the findings of their analyses for a sample of papers. We employed two research scholars to review the coding process. The overall result was $95 \%$ agreement on the findings, making us confident about the reliability of our literature review.

\section{Results}

In this study, we conduct a systematic review of the literature focusing on the role of OHCs as facilitators of value co-creation in the healthcare service ecosystem. In order to answer the research question, thematic analysis has been applied to explore the major concepts of literature regarding the role of OHCs as facilitators in healthcare service ecosystem. This analysis method followed an inductive approach, codding all sections of findings, discussion and conclusion. After following the six steps of thematic analysis including re-reading, re-coding, re-focusing, and refining the content of each paper, three main constructs have been identified as follow;

\section{Value is ubiquitous}

In this study, we found that OHCs are ubiquitous resources that can facilitate value co-creation in all levels of the healthcare service ecosystem. In fact, by using OHCs, the process of value co-creation 
facilitate among actors all across the healthcare ecosystem. Value co-creation occurs in multiple levels of ecosystem ranging from micro level to mega level. Among 22 studies, 11 studies contended that value co-creation process occurs in multiple levels of healthcare service ecosystem. The literature mostly focused on the patient-to-patient interactions in micro level. For example, social and emotional support from peer patients in the OHCs affected patients' perception regarding the service quality of healthcare organisations in the micro and meso levels of the healthcare service ecosystem. Furthermore, each level of an ecosystem includes various kinds of actors and these actors are engaging in the value co-creation process. For instance, on a micro level, patients, physicians, nurses, families and friends, on the meso and macro levels, hospitals, local health agencies, and healthcare organisations, and on the mega level, government health agencies, health funding bodies and regulatory bodies are the main actors. Moreover, numerous interactions occur among different actors such as dyad, triad, and complex networks in the healthcare service ecosystem. Therefore, all interactions in OHCs within and across all levels of the ecosystem grouped into "actors' online interactions" construct. By providing OHCs for actors in the healthcare service ecosystem, users can play a role as product designers, product testers, and product marketers (Nambisan and Nambisan 2008). As online value co-creation occurs in multiple levels of the ecosystem through OHCs, we categorised different kinds of values that created by actors into "online value" construct. By defining the term "online value" we mean that actors can create value through OHCs regardless of their location. In other word, actors are distance value co-creator in the healthcare ecosystem. They can create an online value from different locations and different levels within the healthcare service ecosystem. Therefore, patients and caregivers are the main beneficiaries of ubiquitous of value within OHCs. In essence, OHCs provide an opportunity for actors such as patients, physicians, caregivers, and nurses to share their health information and contribute in the value co-creation process within and across ecosystem levels (Bidar et al. 2017; Courtney 2013; Van Oerle et al. 2018). Consequently, all defined constructs such as; "Ecosystem levels", "online value", and "actors' online interactions" are combined into "ubiquitous value" construct due to the similarity of the context in order to answer the research question.

\section{Online resources connectivism}

In this study, we found that online resources have been generated, shared, and re-combined by actors in OHCs. Resources are crucial parts of value co-creation in healthcare service ecosystem. The outcome of thematic analysis reveals that shared knowledge, health information, members, technology, and organisations within the ecosystem are defined as resources (Barrett et al. 2016; Chandler and Lusch 2015; Ciasullo et al. 2016; Maglio and Spohrer 2013; Osei-Frimpong et al. 2015; Scholz et al. 2017). In this study, we focus on online resources that accessed, shared, and re-combined by actors in the healthcare ecosystem. Accordingly, we investigated three main categories from the literature regarding online resources including; "resource access", "resource sharing", and "resource recombination". OHCs enable users to access, share, and recombine the resources in order to create online value in the healthcare ecosystem. As 8 studies out of 22 articles opined that for beneficial outcomes of value cocreation process, resources require to be combined with other resources (Beirão et al. 2017; Chung 2013; Ciasullo et al. 2017; Ciasullo et al. 2016; Hammervoll 2014; Osei-Frimpong et al. 2015; Palumbo et al. 2017; van der Eijk et al. 2013). As an example of online resource sharing, the patient assisted with this new knowledge can share and discuss with other patients on an OHC. Within the OHCs that form part of the ecosystem, interactions and relationships might change as knowledge is shared (Frow et al. 2016). The knowledge and the resources that shared in OHCs by stakeholders, can be valuable for healthcare professionals, who can read posts, or discussion among members of OHCs, and thereby learn about patients' perceptions, feelings, experiences, and attitudes toward medical services (Zhao et al. 2015). This knowledge also enables physicians to design more effective treatment choices, enhance their service quality, and interact with their patients in an effective way (Zhao et al. 2015). Hence, OHCs can facilitate the process of value co-creation by providing online resources to different actors in the healthcare service ecosystem.

\section{Informational and emotional online support}

OHCs provide informational and emotional support for the community members. These types of supports are co-created by actors in OHCs. Members of these communities, interact online with others to receive and provide different types of social and informational support (Wang et al. 2017). Informational support is the most popular support provided by OHCs (Wang et al. 2017). Actors can benefit from OHCs by obtaining online supports from other actors such as patients, caregivers, physicians, and healthcare organisations. For instance, there are numerous support groups on OHCs such as breast cancer support group of Facebook or support groups of chronic diseases, which were found in the 22 studies. These communities are significant sources of value co-creation for actors in the healthcare service ecosystem. In this study, we explored constructs known as "informational support" 
and "emotional support" that offered by OHCs to participants. Due to the fact that informational and emotional supports are provided through online platforms, the terms "online support" has been named to the construct. In addition, most relevant papers of this study focused on the role of OHCs in value cocreation among actors as in OHCs the process of value co-creation happens between patients, physicians, caregivers, and healthcare organisations. Therefore, OHCs are ideal platforms to foster value co-creation among actors within and across all levels of healthcare service ecosystem.

\section{Discussion and directions for future works}

The results of this study identified three main constructs of literature mostly focusing on value cocreation in the healthcare service ecosystem over the last five years. As the literature contends that value is the basic outcome and the most frequent factor of the co-creation process, this paper thematically analyses the value co-creation process in the healthcare service ecosystem from the context of online value co-creation. In essence, healthcare is not merely delivering of services from hospital or health organisations to patients, but a co-creating of value in which several actors are involved in resource integration in order to exchange service (Gambarov et al. 2017). This review suggests that OHCs provide an ideal platform for fostering value co-creation among different actors in the healthcare service ecosystem. The thematic analysis reveals three main constructs; in the first place, the ubiquitous of value provide opportunities for stakeholders to co-create value regardless of their locations. In the second place, users of OHCs benefit from online resources. For instance, they can access, share, and integrate resources in OHCs within or across levels of the healthcare service ecosystem. Furthermore, healthcare professionals also benefit from sharing resources in OHCs as they can read posts or discussion among members of OHCs, and thereby learn about patients' perceptions, feelings, experiences, and attitudes toward medical services (Zhao et al. 2015). In the third place, actors can leverage OHCs by gaining online supports from other such as patients, caregivers, physicians, and healthcare organisations in order to provide different types of social and informational support.

It is important for service managers to extend their perspective to all actors in the service ecosystem by understanding the significance of mutual value co-creation at the system level (Beirão et al. 2017).In this systematic review, we also adopt a developed view of Gummesson (2008) regarding the levels of service ecosystem, placing particular focus on the mega level as this level was not mentioned in some previous studies as one of the ecosystem levels. In essence, mega level plays important role in the healthcare service ecosystem. Therefore, in this study, we adopt four levels of a service ecosystem; micro, meso, macro and mega level as our research question focused on healthcare service ecosystem. Healthcare organisations should establish better relations with the different actors at the other levels for value co-creation. Moreover, there is a need to design proper policies to elude the emergence of value co-destruction, which contains negative health outcomes (Barile et al. 2016). Therefore, healthcare organisations need to provide active patients with opportunities to engage in widespread value cocreation (Jaakkola and Alexander 2014). In doing so, OHCs can be applied as part of the healthcare organisation service offerings to increase the quality and value of their service portfolio in a cost-effective manner (Nambisan and Nambisan 2009).

Although numerous businesses have started to harness the advance potential of online communities by utilizing them as an online environment for customer co-innovation and value co-creation, healthcare organisations are lagging behind (Amann et al. 2016; Nambisan 2002). To date, more and more healthcare organisations are recognising the importance of OHCs as a significant platform of complementary service to improve the total quality of healthcare services delivery (Amann and Rubinelli 2017). Hence, healthcare organisations can extend a better understanding of various types of consumer value co-creation that is delivered by OHCs (Nambisan and Nambisan 2009). However, only limited studies have provided holistic view toward the significance of health service co-production and value cocreation in shaping a dynamic healthcare ecosystem (Annarumma and Palumbo 2016; Beirão et al. 2017; Frow et al. 2016). There is also a lack of sufficient studies regarding how interactions among multiple actors, especially in meso, macro and mega level, contribute to the emergence of value co-creation process (Ciasullo et al. 2016). Besides, the perspective in which healthcare organisations are able to participate indirectly in value co-creation might be an area of investigation (Hardyman et al. 2015). Furthermore, while in a complex domain such as healthcare, the service ecosystem view suggest a comprehensive understanding of value co-creation between the actors (Ciasullo et al. 2017), not many authors have focused on meso, macro and mega level. For instance, Hardyman et al. (2015 have investigated the interactions between healthcare organisations, local health agencies, and social services in the meso level. Consequently, only a few studies are exploring the value co-creation at macro and mega level (Frow et al. 2016; McColl-Kennedy et al. 2012). Thus, there are a number of areas, which is required for further research and discussion concerning value co-creation in healthcare service 
ecosystem especially, engagement of healthcare organisations in meso level along with investigating the role of OHCs as facilitators within or across ecosystem levels.

\section{Conclusion}

This paper has investigated an online value co-creation in the healthcare service ecosystem. In doing so, relevant studies have been considered to interpret the significance of value co-creation in the healthcare service ecosystem. As social technologies such as online communities embedded in ecosystems, it is essential to understand how technology enables ecosystem emergence and provide opportunities for ecosystem actors. In a complex domain such as healthcare, the service ecosystem view suggest a comprehensive understanding of value co-creation between the actors (Ciasullo et al. 2017). The ecosystem's view leads to a great understanding of the necessity for resources' combinations, which is a fundamental aspect of value co-creation (Pappa et al. 2017). From co-creation perspective in a healthcare domain, patients are not passive and recipient of healthcare services, however rather are active co-creator of value, and there is increasing evidence that benefits of such a method include enhancing health outcomes and cost efficiencies (Frow et al. 2016). At the micro level, the quality of healthcare services provided to patients influences a healthcare organisation's total service quality, which in turn impact the patient's quality of life (Beirão et al. 2017). For example, social and emotional support from peer patients in the OHCs affected patients' perception regarding the service quality of healthcare organisations. Additionally, healthcare professionals should engage with patients and caregivers in co-designing and co-delivering health treatments (Palumbo et al. 2017). At the meso level, based on the outcome of thematic analysis, healthcare organisations should attempt to provide healthcare environment that establishes a co-creation of value among actors in the healthcare domain (Palumbo et al. 2017). Healthcare organisations need to take a holistic view of service delivery, considering the critical areas of the co-creation process for providing an opportunity for patients for an active participatory role in healthcare as healthcare is a high participatory domain and it needs patients active participation to attain successful results (Osei-Frimpong et al. 2015). At the macro and mega levels, governmental health agencies should be attentive about the role of vivid and cooperative interorganisational relationship in identifying the potential of value co-creation (Palumbo et al. 2017). The mega level plays an essential role in establishing a healthcare service ecosystem (Palumbo et al. 2017). In essence, this level might improve patient-centred care at the macro and meso level that has the potential to enhance the suitability of the healthcare services ecosystem (Frow et al. 2014). Government health agencies can impact on the organisational strategies, motivating them to obey an ecosystem strategies at the strategic and the operational level (Adner 2017). Nevertheless, previous studies have emphasised on empowerment of patients in micro level (Funnell 2016), healthcare organisations should also be taken into consideration regarding empowerment to participate in value co-creation process (Palumbo et al. 2017). OHCs can improve the process of value co-creation among patients along with providing with an additional mechanism for obtaining informational and emotional support. These new forms of user-generated contents might offer value to patients, healthcare professionals, and healthcare organisations (Barrett et al. 2016). Practitioners should also be aware of environmental and cognitive impacts on users to improve value co-creation behaviour, improving the success of online communities (Bidar et al. 2016). Participation in OHCs leads to additional activities carrying out by patients, that add value to the patient-provider interactions (Hartmann et al. 2015). The information synthesised from the literature in this systematic review also suggest that the value co-creation is not limited to a micro level, which focuses on the dyadic interactions between patients and providers; rather their effect extends to all ecosystems' levels. In fact, the different actors such as patients, physicians, healthcare organisations, caregivers, professional association, etc., are participated in various ways regarding value co-creation, contributing health outcome enhancement at all levels.

\section{Reference}

Adner, R. 2017. "Ecosystem as Structure: An Actionable Construct for Strategy," Journal of Management (43:1), pp. 39-58.

Akaka, M. A., Vargo, S. L., and Lusch, R. F. 2013. "The Complexity of Context: A Service Ecosystems Approach for International Marketing," Journal of Marketing Research (21:4), pp. 1-20.

Amann, J. 2017. "Democratising Healthcare: The Role of Ehealth Technologies in Driving Patient Participation," EMJ Innov (1:1), pp. 40-46.

Amann, J., and Rubinelli, S. 2017. "Views of Community Managers on Knowledge Co-Creation in Online Communities for People with Disabilities: Qualitative Study," J Med Internet Res (19:10), p. e320. 
Amann, J., Zanini, C., and Rubinelli, S. 2016. "What Online User Innovation Communities Can Teach Us About Capturing the Experiences of Patients Living with Chronic Health Conditions. A Scoping Review," PloS one (11:6), p. e0156175.

Annarumma, C., and Palumbo, R. 2016. "Contextualizing Health Literacy to Health Care Organizations: Exploratory Insights," Journal of Health Management (18:4), pp. 611-624.

Arvidsson, A. 2008. "The Ethical Economy of Customer Coproduction," Journal of Macromarketing (28:4), pp. 326-338.

Barile, S., Lusch, R., Reynoso, J., Saviano, M., and Spohrer, J. 2016. "Systems, Networks, and Ecosystems in Service Research," Journal of Service Management (27:4), pp. 652-674.

Barrett, M., Oborn, E., and Orlikowski, W. 2016. "Creating Value in Online Communities: The Sociomaterial Configuring of Strategy, Platform, and Stakeholder Engagement," Information Systems Research (27:4), pp. 704-723.

Beirão, G., Patrício, L., and Fisk, R. P. 2017. "Value Cocreation in Service Ecosystems: Investigating Health Care at the Micro, Meso, and Macro Levels," Journal of Service Management (28:2), pp. 227-249.

Bidar, R., Watson, J., and Barros, A. 2017. "Classification of Service Co-Creation Systems: An Integrative Approach," Advanced Communication Technology (ICACT), 2017 19th International Conference on: IEEE, pp. 333-340.

Bidar, R., Watson, J., and Barros, A. P. 2016. "Literature Review to Determine Environmental and Cognitive Factors Underlying User Value Cocreation Behaviour,").

Braun, V., and Clarke, V. 2006. "Using Thematic Analysis in Psychology," Qualitative research in psychology (3:2), pp. 77-101.

Chandler, J. D., and Lusch, R. F. 2015. "Service Systems: A Broadened Framework and Research Agenda on Value Propositions, Engagement, and Service Experience," Journal of Service Research (18:1), pp. 6-22.

Chung, J. E. 2013. "Patient-Provider Discussion of Online Health Information: Results from the 2007 Health Information National Trends Survey (Hints)," Journal of health communication (18:6), pp. 627-648.

Ciasullo, M. V., Cosimato, S., and Palumbo, R. 2017. "Value Co-Creation in the Health Service Ecosystems: The Enabling Role of Institutional Arrangements," International Business Research (10:12), p. 222.

Ciasullo, M. V., Cosimato, S., Storlazzi, A., and Douglas, A. 2016. "Health Care Ecosystem: Some Evidence from the International Consortium for Health Outcomes Measurement (Ichom)," Toulon-Verona Conference" Excellence in Services".

Courtney, K. 2013. "The Use of Social Media in Healthcare: Organizational, Clinical, and Patient Perspectives," Enabling health and healthcare through ICT: available, tailored and closer (183), p. 244.

Frow, P., McColl-Kennedy, J. R., Hilton, T., Davidson, A., Payne, A., and Brozovic, D. 2014. "Value Propositions: A Service Ecosystems Perspective," Marketing Theory (14:3), pp. 327-351.

Frow, P., McColl-Kennedy, J. R., and Payne, A. 2016. "Co-Creation Practices: Their Role in Shaping a Health Care Ecosystem," Industrial Marketing Management (56), pp. 24-39.

Funnell, M. M. 2016. "Patient Empowerment: What Does It Really Mean?," Patient education and counseling (99:12), pp. 1921-1922.

Gambarov, V., Sarno, D., Hysa, X., Calabrese, M., and Bilotta, A. 2017. "The Role of Loyalty Programs in Healthcare Service Ecosystems," The TQM Journal (29:6), pp. 899-919.

Gummesson, E. 2008. "Extending the Service-Dominant Logic: From Customer Centricity to Balanced Centricity," Journal of the Academy of Marketing Science (36:1), pp. 15-17.

Hammervoll, T. 2014. "Service Provision for Co-Creation of Value: Insights from Exchange-and Production Economy Perspectives," International Journal of Physical Distribution \& Logistics Management (44:1/2), pp. 155-168.

Hardyman, W., Daunt, K. L., and Kitchener, M. 2015. "Value Co-Creation through Patient Engagement in Health Care: A Micro-Level Approach and Research Agenda," Public Management Review (17:1), pp. 90-107.

Hartmann, B. J., Wiertz, C., and Arnould, E. J. 2015. "Exploring Consumptive Moments of ValueCreating Practice in Online Community," Psychology \& Marketing (32:3), pp. 319-340.

Jaakkola, E., and Alexander, M. 2014. "The Role of Customer Engagement Behavior in Value CoCreation: A Service System Perspective," Journal of Service Research (17:3), pp. 247-261.

Lusch, R. F., and Spohrer, J. C. 2012. "Evolving Service for a Complex, Resilient, and Sustainable World," Journal of Marketing Management (28:13-14), pp. 1491-1503.

Lusch, R. F., and Vargo, S. L. 2014. Service-Dominant Logic: Premises, Perspectives, Possibilities. Cambridge University Press. 
Lusch, R. F., Vargo, S. L., and O'brien, M. 2007. "Competing through Service: Insights from ServiceDominant Logic," Journal of retailing (83:1), pp. 5-18.

Maglio, P. P., and Spohrer, J. 2013. "A Service Science Perspective on Business Model Innovation," Industrial Marketing Management (42:5), pp. 665-670.

McColl-Kennedy, J. R., Vargo, S. L., Dagger, T. S., Sweeney, J. C., and Kasteren, Y. v. 2012. "Health Care Customer Value Cocreation Practice Styles," Journal of Service Research (15:4), pp. 370-389.

Nambisan, P., and Nambisan, S. 2009. "Models of Consumer Value Cocreation in Health Care," Health Care Management Review (34:4), pp. 344-354.

Nambisan, S. 2002. "Designing Virtual Customer Environments for New Product Development: Toward a Theory," Academy of Management Review (27:3), pp. 392-413.

Nambisan, S., and Nambisan, P. 2008. "How to Profit from a Better'virtual Customer Environment'," MIT Sloan management review (49:3), p. 53.

Nili, A., Tate, M., and Barros, A. 2017. "A Critical Analysis of Inter-Coder Reliability Methods in Information Systems Research,").

Nili, A., Tate, M., and Johnstone, D. 2018. "The Process of Solving Problems with Self-Service Technologies: A Study from the User's Perspective," Electronic Commerce Research), pp. 1-35.

Osei-Frimpong, K., Wilson, A., and Lemke, F. 2018. "Patient Co-Creation Activities in Healthcare Service Delivery at the Micro Level: The Influence of Online Access to Healthcare Information," Technological Forecasting and Social Change (126), pp. 14-27.

Osei-Frimpong, K., Wilson, A., and Owusu-Frimpong, N. 2015. "Service Experiences and Dyadic Value Co-Creation in Healthcare Service Delivery: A Cit Approach," Journal of Service Theory and Practice (25:4), pp. 443-462.

Palumbo, R., Cosimato, S., and Tommasetti, A. 2017. "Dream or Reality? A Recipe for Sustainable and Innovative Health Care Ecosystems," The TQM Journal (29:6), pp. 847-862.

Pappa, G. L., Cunha, T. O., Bicalho, P. V., Ribeiro, A., Couto Silva, A. P., Meira, W., Jr., and Beleigoli, A. M. 2017. "Factors Associated with Weight Change in Online Weight Management Communities: A Case Study in the Loseit Reddit Community," J Med Internet Res (19:1), p. e17.

Peters, C., Bodkin, C. D., and Fitzgerald, S. 2012. "Toward an Understanding of Meaning Creation Via the Collective Co-Production Process," Journal of Consumer Behaviour (11:2), pp. 124-135.

Pinho, N., Beirão, G., Patrício, L., and P. Fisk, R. 2014. "Understanding Value Co-Creation in Complex Services with Many Actors," Journal of Service Management (25:4), pp. 470-493.

Romero, D., and Molina, A. 2011. "Collaborative Networked Organisations and Customer Communities: Value Co-Creation and Co-Innovation in the Networking Era," Production Planning \& Control (22:5-6), pp. 447-472.

Scholz, B., Bocking, J., and Happell, B. 2017. "How Do Consumer Leaders Co-Create Value in Mental Health Organisations?," Australian Health Review (41:5), pp. 505-510.

Tapscott, D., and Williams, A. D. 2008. Wikinomics: How Mass Collaboration Changes Everything. Penguin.

van der Eijk, M., Faber, M. J., Aarts, J. W., Kremer, J. A., Munneke, M., and Bloem, B. R. 2013. "Using Online Health Communities to Deliver Patient-Centered Care to People with Chronic Conditions," Journal of medical Internet research (15:6).

Van Oerle, S., Lievens, A., and Mahr, D. 2018. "Value Co-Creation in Online Healthcare Communities: The Impact of Patients' Reference Frames on Cure and Care," Psychology \& Marketing).

Vargo, S. L., and Lusch, R. F. 2004. "Evolving to a New Dominant Logic for Marketing," Journal of marketing (68:1), pp. 1-17.

Vargo, S. L., and Lusch, R. F. 2011. "It's All B2b... and Beyond: Toward a Systems Perspective of the Market," Industrial marketing management (40:2), pp. 181-187.

Wang, X., Zhao, K., and Street, N. 2017. "Analyzing and Predicting User Participations in Online Health Communities: A Social Support Perspective," Journal of medical Internet research (19:4).

Zhao, J., Wang, T., and Fan, X. 2015. "Patient Value Co-Creation in Online Health Communities: Social Identity Effects on Customer Knowledge Contributions and Membership Continuance Intentions in Online Health Communities," Journal of Service Management (26:1), pp. 72-96.

Copyright: (C) 2018 Rezaei Aghdam, Watson, Ziaimatin. This is an open-access article distributed under the terms of the Creative Commons Attribution-Non Commercial 3.o Australia License, which permits non-commercial use, distribution, and reproduction in any medium, provided the original author and ACIS are credited. 